\title{
An accelerated test for concrete
}

\author{
Accelerated Testing Committee, \\ Chairman, Professor J. W. H. King
}

\section{Dr L. J. Murdock, Central Laboratory, George Wimpey \& Co. Ltd}

The Research and Development Report gives laboratory tests on an accelerated test for concrete. Among the objectives of the Accelerated Testing Committee was the evolution of a 'reliable standard test which would be simple enough for field use and take a day or less to complete'. In $\S 9$ the Committee expresses the view 'that the accelerated test should not be used simply to predict the 28 day strength, but that it should be used as a quality control in its own right'. The Report, however, does not deal with the practical problems which arise in the field, and there are objections to the use of the test unless it is accompanied by cube testing at a reasonably fully mature age, generally accepted as 28 days.

17. The conditions of test rule out the possibility of transport of cubes from the point at which they are made to another location for testing. This virtually means that the tests have to be made on site. Several problems then arise.

18. Testing machines have to be provided on all sites and have to be kept in good order with calibration at intervals. As a testing machine costs at least $£ 750$, the capital involved can be considerable. Also, cheap hand-operated testing machines are notoriously inaccurate.

19. No matter whether the accelerated tests are to be made by the resident engineer's staff or by the contractor's staff, additional costs will be involved in setting up a site laboratory with an experienced technician. This represents an additional cost to the client which at the present time is not incurred on the great majority of building and civil engineering contracts.

20. Except on large works, it is unlikely that a resident engineer and testing staff will be available to ensure that the cubes are cured at the correct temperature, and that the tests are properly done and reported. If, therefore, on the great majority of sites the accelerated test were to be adopted as the sole test, there would then be no independent off-site check on the quality of the concrete. This would obviously be against the client's interests.

21. Other problems which would arise in practice when using a one day test are that testing personnel will have to be on site on Saturday or Sunday if concrete is made on the previous Friday or Saturday, respectively. This could raise quite serious problems and possibly considerable extra expense in overtime payments.

22. If the one day accelerated test is the sole test, then the aim of ready-mixed concrete suppliers, the cement industry and all others connected with the manufacture of concrete, will be to produce test specimens which satisfy this criterion. Admixtures might be used or developed for this purpose, and there would be a strong temptation for the cement manufacturers to produce their cements with this criterion in mind, to the possible detriment of durability and other desirable properties.

23. If the purpose is to provide strong durable concrete with an effective life of many decades, a long-term check test is essential, and reliance on a one day accelerated test only could have unfortunate consequences.

24. The use of this accelerated test may assist on large sites with adequate technical staff, or in cases where an employing authority is controlling various works within a limited area. However, these form only a very small proportion of all

Report published: Proc. Instn civ. Engrs, 1968, 40 (May) 125-133. 
concreting works. Economic and practical considerations are likely to rule the test out on the great majority of sites. The very small amount of concrete which is cut out as a result of cube failures or other evidence of unsatisfactory material indicates that present control measures, mainly by tests for cube strength, are commercially satisfactory, and it is questionable whether any increased expenditure would be justified.

\section{Professor King}

It appears that whilst some of Dr Murdock's criticisms of the accelerated test may apply to small contracts where little if any testing of concrete is carried out, they are of small moment on larger contracts where it would be normal practice to have a site laboratory or at least some arrangements for sampling, casting and curing.

26. On the cost of testing machines, even $£ 750$ is a small amount compared with the total plant cost on any but the smallest site. In any case, the depreciation rate for such a machine is very low, and it would not be unreasonable to write it off over 20 years as a minimum. Surely $15 \mathrm{~s} /$ week is not a high cost. Incidentally, there are some very good hand-operated machines on the market.

27. Again, in relation to the contract cost, the costs of site laboratory and technician, and of curing and testing, are small. If testing is carried out at all, there must be someone responsible for making and controlling at least the initial curing of cubes which should be demoulded after 24 hours for the present 28 day test, and cured throughout under controlled conditions. The extra work involved in actually testing the cubes on demoulding is insignificant. Dr Murdock surely insists on proper control in the important initial $24 \mathrm{~h}$ of the 28 day tests.

28. As regards the client, the Committee maintains that a rapid test in 24 hours or so is so much more in his interest than the $\mathbf{2 8}$ day test that even considerable extra cost would be borne with equanimity.

29. I am sure that the cement industry would not prepare cement to give a good $24 \mathrm{~h}$ test to the detriment of long-term strength in the structure. Most contracts specify the cement and any permitted admixtures, and neither the cement industry nor the contractor can legally alter these to obtain a good $24 \mathrm{~h}$ strength without the knowledge and agreement of the client, who would surely not agree to imperil his structure for the sake of a good $24 \mathrm{~h}$ strength. He would therefore not permit unfamiliar cements and admixtures without ad hoc tests on a long-term basis. This, however, does not in any way militate against the use of the $24 \mathrm{~h}$ test for known cements, a point which was emphasized in the Report.

30. With reference to the present small amount of cutting out, it would be more relevant to consider the amount of bad concrete which may be allowed to remain because of the impracticability of removing it 28 days after placing. If this were known it would, I think, put the $24 \mathrm{~h}$ test well ahead of the current 28 day test for reliable control on site, since the cutting out of $24 \mathrm{~h}$ concrete would usually be practicable. 